\title{
ВЕЩЕСТВЕННЫЙ СОСТАВ ФОСФОРИТОНОСНЫХ ПОРОД МЕСТОРОЖДЕНИЯ ТООЛСЕ
}

Эстонские т. н. ракушечниковые фосфориты широко распространены в Северной и местами в Западной Эстонии (Kivimägi, 1971). К настоящему времени разведаны месторождения фосфоритов Маарду, Тситре-Валкла, Азери-Сака, Нарва и Тоолсе. Наиболее крупным из них является месторождение Тоолсе (Мустйыги, 1970; Раудсеп, 1971). Ниже дается характеристика вещественного состава фосфоритов этого месторождения. Составлена она по данным, полученным работниками бывшей партии фосфоритов Управления геологии СМ ЭССР и Московского института ГИГХС (Наливкина, 1973).

\section{Литологический состав}

Маардуская пачка пакерортского горизонта нижнего ордовика представлена разнозернистыми кварцевыми песчаниками разной степени цементации и с разным содержанием детрита, а также фрагментов створок раковин (ракушек) беззамковых брахиопод. Ранее эти песчаники назывались «оболовыми». Мощность пачки колеблется на месторождении Тоолсе от 1,50 до $7,90 \mu$ (в среднем - 4,94 $м$ ).

В отчете детальной разведки месторождения фосфоритов Тоолсе была сделана попытка более детально расчленить маардускую пачку. Выделены следующие разновидности пород (сверху вниз):

1) кварцевый песчаник («пустой песчаник»),

2) детритистый кварцевый песчаник,

3) детритовый песчаник,

4) детритовый брахиоподовый конгломерат,

5) брахиоподовый конгломерат.

При выделении этих разновидностей учитывалось содержание детрита и ракушек брахиопод, степень цементации, размеры зерен и т. д.

К в а рце вы й песч ан и к распространен по всему месторождению и служит кровлей нижележащего промышленного пласта. Представлен алевритовым и мелкозернистым песчаным материалом, составляющим около $80 \%$ от всей массы породы. Чаще всего он коричневато- или желтовато-серого цвета, реже светло-серый. Обычно порода крепко сцементирована (цементом служит пирит базального типа цементации, реже кальцит), содержит многочисленные прослойки диктионемового сланца (черного аргиллита) мощностью до $10 \mathrm{~cm}$. Общей закономерностью слоя является увеличение содержания и размеров детрита сверху вниз по разрезу. Содержание детрита не превышает $10 \%$. Содержание $\mathrm{P}_{2} \mathrm{O}_{5}$, по данным химических анализов, составляет в среднем 2,36\%. Мощность слоя колеблется от 0,10 до 5,5 м. 
Таблица 1

Гранулометрический состав фосфоритоносных песчаников

\begin{tabular}{|c|c|c|c|c|c|c|c|c|c|c|c|}
\hline Разновидности породы & $>10$ & $10-7$ & $7-5$ & $5-3$ & $3-2$ & $2-1$ & $1-0,5$ & $\begin{array}{l}0,5- \\
0,25\end{array}$ & $\begin{array}{c}0,25- \\
0,1\end{array}$ & $<0,1$ & Bcero \\
\hline $\begin{array}{l}\text { Кварцевый песчаник (37 } \\
\text { проб) } \\
\text { Детритистый кварцевый }\end{array}$ & 0,06 & 0,02 & 0,18 & 2,11 & 0,40 & 0,56 & 4,26 & 14,03 & 54,09 & 24,37 & 100,08 \\
\hline $\begin{array}{c}\text { песчаник (74 пробы) } \\
\text { Детритовый песчаник (33 }\end{array}$ & 0,02 & 0,03 & 0,07 & 0,17 & 0,35 & 1,04 & 7,60 & 34,03 & 44,39 & 12,29 & 99,99 \\
\hline $\begin{array}{l}\text { пробы) } \\
\text { Детритовый брахиоподо- } \\
\text { вый конгломерат }(22\end{array}$ & - & 0,01 & 0,01 & 0,09 & 0,28 & 1,77 & 17,12 & 33,76 & 35,93 & 11,02 & 99,99 \\
\hline $\begin{array}{l}\text { пробы) } \\
\text { Брахноподовый конгломе- }\end{array}$ & - & 0,13 & 0,20 & 0,65 & 0,89 & 2,59 & 14,77 & 34,83 & 30,57 & 14,78 & 99,41 \\
\hline рат (6 проб) & - & - & 0,04 & 0,41 & 0,79 & 4,72 & 14,03 & 32,46 & 29,38 & 18,20 & 100,03 \\
\hline
\end{tabular}

Д е т и ти ты й кварцевы й п есчаник почти по всему месторождению покрыт кварцевым и подстилается детритовым песчаником. Представлен он в основном алевритистым мелко- или среднезернистым песчаником с примесью крупной фракции (количество увеличивается вниз по разрезу, табл. 1) серого, местами коричневато- и желтоватого цветов. Порода в основном слабо- или среднесцементирована, содержит мелкий $(0,1-0,25$ мм) или средний $(0,25-0,5$ мм) по величине детрит брахиоподовых ракушек. Изредка встречаются прослойки диктионемового сланца (мощностью до 1,0 cм). Детрит обычно черного цвета, реже коричневатый или зеленоватый. Содержание его в породе достигает $17-18 \%$, содержание $\mathrm{P}_{2} \mathrm{O}_{5}$ составляет в среднем $5,55 \%$. Мощность слоя колеблется от 0,20 до $2,50 \mathrm{M}$, в среднем $1,0-1,5 \mathrm{M}$. На юго-востоке месторождения этот слой выклинивается.

По сравнению с кварцевым песчаником детритистый кварцевый песчаник содержит больше детрита (более 10\%), слабее сцементирован, более темноцветен и содержит меньше прослоек диктионемового сланца; размеры зерен песчаных частиц более крупные.

Д етр и товы й песч ан ик слагает среднюю часть разреза маардуской пачки. Обычно на нем залегает детритистый кварцевый песчаник, а подошвой является детритовый брахиоподовый, реже брахиоподовый конгломерат. Представлен серым, иногда коричневато- или зеленоватосерым, мелко- и среднезернистым песчаником (табл. 1). Порода обычно средне-, реже крепкосцементирована. Цементом служит пирит или кальцит. Детрит в песчанике серого или черного цвета, часто покрыт пленкой или мелкими кристаллами пирита. Его содержание варьирует в пределах от 25 до $50-60 \%$. Содержание $\mathrm{P}_{2} \mathrm{O}_{5}$ составляет в среднем 9,57\%. Детритовый песчаник распространен почти повсеместно на территории месторождения. Мощность его колеблется от 0,30 до 1,70 м. По сравнению с вышележащим детритистым кварцевым песчаником здесь больше детрита (более $25 \%$ ) и размеры зерен более крупные.

Д етритовы й брахиоподовы й конгломерат залегает в нижней части разреза маардуской пачки, кровлей служит обычно детритовый песчаник, а подошвой - кембрийские алевролиты, реже брахиоподовый конгломерат. Обычно он темно-серого или черного цветов, степень цементации - от средней до крепкой. Цементом служат обычно доломит и кальцит, реже пирит, образуя поровой тип цементации. Содержание детрита в породе достигает $50-70 \%$, содержание $\mathrm{P}_{2} \mathrm{O}_{5}$ составляет в среднем $17,82 \%$. Среди песчаного материала преобладают средне- и 
мелкозернистая фракции (табл. 1). Распространен на месторождении повсеместно. Мощность колеблется от 0,10 до $1,40 \mathrm{\mu}$. Основное отличие от детритового песчаника заключается в повышенных содержаниях детрита и фрагментов ракушек брахиопод, размеры которых гораздо крупнее.

Брах иоподовый конгломе р а т слагает самую нижнюю часть маардуской пачки. Чаще всего он покрыт детритовым брахиоподовым конгломератом, а залегает на тискреских алевролитах. Обычно крепкосцементирован, имеет цвет темно-серый или черный. Сложен главным образом крупными фрагментами ракушек брахиопод $(\sim 80 \%)$, кварцем и карбонатами. Последние образуют базальный цемент. Среднее содержание $\mathrm{P}_{2} \mathrm{O}_{5}-18,67 \%$. Мощность слоя колеблется от 0,0 до $0,70 \mathrm{M}$. По сравнению с детритовым брахиоподовым конгломератом здесь почти нет мелкого детрита ракушек брахиопод.

В целом фосфатная руда - это песчаник в различной степени обогащенный створками раковин брахиопод и их детритом, вплоть до ракушечника. Основную массу $(\sim 82,5 \%)$ составляют зерна от 0,1 до 1,0 мм. Мощность промышленного пласта в целом колеблется от 0,7 до $5,2 \mathrm{M}$, составляя в среднем 2,9 м. Общая закономерность - уменьшение мощности на восток и юго-восток месторождения.

\section{Минералогический состав}

Минералогический состав руды относительно однообразный: кварц, фосфаты, пирит и другие породообразующие минералы.

Основную массу руды слагает к в а ц, который представлен хорошо окатанными, прозрачными, реже полупрозрачными зернами. В мелких фракциях $(<0,1$ мм) встречаются иногда неокатанные зерна. Часто зерна кварца покрыты пленкой фосфата и микрокристаллами пирита. Средний размер зерен варьирует от 0,1 до 0,5 мм, а в брахиоподовом конгломерате достигает 1,0 мм.

Фосфатны е минер алы представлены фосфатом, слагающим раковины и их обломки, фосфатом, слагающим пленки на зернах кварца, и фосфатами железа.

$Ф$ осфат, сл аг а ющй р а ков и ны минералогически представлен раскристаллизованным фторкарбонатапатитом, содержащим $\mathrm{P}_{2} \mathrm{O}_{5}$ до $35-36 \%$. Для детрита и створок раковин, содержащихся в фосфоритах, характерен черно- или темно-серый цвет, обусловленный тонкораспыленным в них пиритом. В районе глинта, а также в верхней половине разреза встречаются светло-серые, белые или светло-желтые и коричневые раковины и обломки за счет окисления пирита и органического вещества.

Фосфат, сл агающи й пленки на зернах кварца, представлен радиально-лучистым фосфатом. Содержание $\mathrm{P}_{2} \mathrm{O}_{5}$ в нем составляет $38 \%$, показатель преломления равен 1,626.

$\Phi$ осфаты желез а представлены виви анитом $\left[\mathrm{Fe}_{3}\left(\mathrm{PO}_{4}\right)_{2}\right.$. . $\left.8 \mathrm{H}_{2} \mathrm{O}\right]$, который образует радиально-лучистые формы или мелкоигольчатые кристаллы от темно-синего до черного или желтовато-зеленого цветов. В некоторых разрезах вивианит присутствует в виде плотной землистой массы почти черного цвета. Фосфаты железа встречаются редко и только в северной (приглинтовой) части месторождения, а также в верхней части промышленного пласта - детритистом песчанике.

Минералы желез а широко распространены на месторождении. Они представлены в основном сульфидами и гидроокислами железа, и в меньшей мере - силикатами и карбонатами железа. 
Сульфиды железа представлены пиритом, который встречается в основном в виде мелких кристалликов размерами 0,2 мм и менее, тонко распыленными в фосфатных раковинах и их обломках. Кроме того, они образуют сыпь на зернах кварца.

Гидроокислы желез а образуют пленки на зернах кварца и реже на кристаллах других минералов, а также стяжения и оолиты во вмещающей породе, окрашивая ее в ярко-красный и охристо-желтый цвета.

Карбонаты железа находятся в виде изоморфной примеси в составе доломита, который цементирует брахиоподовый и детритовый брахиоподовый конгломераты.

С или к а ты желез а присутствуют в составе глинистых минералов в диктионемовых сланцах, частично распылены среди карбонатного цемента и входят в состав глауконита.

К арбонатные минералы представлены доломитом и кальцитом.

Долом и т цементирует зерна кварца и фосфатные раковины в детритовом брахиоподовом и брахиоподовом конгломератах. Микроскопически это крупные кристаллы. Общее количество доломита в цементированных прослоях составляет $20 \%$ от массы породы. Кроме того, до.томит корродирует зерна кварца и проникает в фосфатные ракушки.

К альци т - малораспространенный на месторождении минерал. Вместе с доломитом он присутствует в цементе брахиоподового конгломерата в виде агрегатных образований.

Слюдисты е минералы представлены глауконитом и гидрослюдами.

Гл ау кон и т образует овальные, ярко-зеленые, слабоплеохроичные зерна агрегатного строения.

Г и д р осл юд ы составляют основную часть диктионемовых сланцев.

Минералогический состав фосфоритной руды Тоолсе в целом не отличается от состава месторождений Маарду и Кингисепп. Однако нужно отметить, что в породах Кингисеппского месторождения обнаружено довольно высокое содержание доломита, особенно в доломитизирован ных песчаниках, а содержание пирита и фосфатов, наоборот, относительно низкое (табл. 2).

\section{Химический состав}

Как известно, в фосфоритах основное количество полезного компонента $\mathrm{P}_{2} \mathrm{O}_{5}$ содержат ракушки разных беззамковых брахиопод. Роль фосфоритовых галек, фосфатных минералов, содержащихся в песчанике, и фосфатного цемента - гораздо меньше.

Химический состав ракушек брахиопод, собранных на месторождении Тоолсе, изучен в 12 пробах. Пробы были отобраны главным образом из детритового и брахиоподового конгломератов. Никаких существенных отличий в химическом составе ракушек как в вертикальном, так и в горизонтальном направлении не обнаружено.

По сравнению с другими месторождениями фосфоритов Әстонии содержание $\mathrm{P}_{2} \mathrm{O}_{5}$ в фосфатных ракушках Тоолсе несколько ниже, а содержание нерастворимого остатка (н. о.), наоборот, выше. Установлены также пониженные концентрации $\mathrm{F}, \mathrm{CaO}$ и, напротив, повышенные концентрации $\mathrm{MgO}, \mathrm{CO}_{2}$.

Химический состав фосфоритоносных песчаников изучался по всем горным выработкам. Средний химический состав промышленного пласта 
Таблица 2

Минералогический состав фосфоритов месторождений Маарду, Тоолсе и Кингисепп

\begin{tabular}{|c|c|c|c|c|c|}
\hline \multirow{3}{*}{ Минералы } & \multicolumn{5}{|c|}{ Содержание минералов по месторождениям, \% } \\
\hline & \multirow[b]{2}{*}{ Маарду * } & \multicolumn{2}{|c|}{ Тоолсе ** } & \multicolumn{2}{|c|}{ Кингисепп } \\
\hline & & $\begin{array}{c}\text { вся маар- } \\
\text { дуская } \\
\text { пачка }\end{array}$ & $\begin{array}{l}\text { промыш- } \\
\text { ленный } \\
\text { пласт }\end{array}$ & $\begin{array}{c}\text { средне- } \\
\text { зернистые } \\
\text { пескі }\end{array}$ & $\begin{array}{c}\text { доломити- } \\
\text { зированные } \\
\text { песчаники }\end{array}$ \\
\hline Кварц & $15-90$ & 67,5 & 66,0 & 80,0 & 64,0 \\
\hline Фосфаты & $10-85$ & 24,1 & 29,2 & 14,0 & 10,0 \\
\hline Пирит & ед. зерна & 1,2 & 0,6 & мало & ред. зерна \\
\hline Карбонаты & - & 1,6 & 0,8 & 5,0 & 25,0 \\
\hline в том числе доломит & - & 0,4 & 0,4 & - & 25,0 \\
\hline Окислы железа & - & 0,04 & 0,04 & - & - \\
\hline Гидроокислы железа & - & 0,1 & 0,01 & 1,0 & 1,0 \\
\hline Глауконит & ед. зерна & 0,4 & 0,2 & ед. зерна & ред. зерна \\
\hline Полевые шпаты & - & 0,8 & 0,5 & ед. зерна & - \\
\hline
\end{tabular}

По данным детальных разведок. * 1960-1961 гг. ** 1969-1971 гг.

Таблица 3

Средний химический состав фосфоритов месторождения Тоолсе

\begin{tabular}{|c|c|c|c|c|c|}
\hline \multirow[b]{2}{*}{$\begin{array}{c}\text { Компо- } \\
\text { ненты }\end{array}$} & \multicolumn{5}{|c|}{ Среднее содержание, \% } \\
\hline & $\begin{array}{c}\text { Детритис- } \\
\text { тый квар- } \\
\text { цевый } \\
\text { песчаник }\end{array}$ & $\begin{array}{c}\text { Детрито- } \\
\text { вый пес- } \\
\text { чаник }\end{array}$ & $\begin{array}{l}\text { Детрито- } \\
\text { вый бра- } \\
\text { хиоподо- } \\
\text { вый кон- } \\
\text { гломерат }\end{array}$ & $\begin{array}{c}\text { Брахио- } \\
\text { подовый } \\
\text { конгло- } \\
\text { мерат }\end{array}$ & $\begin{array}{c}\text { Промышленный } \\
\text { пласт }\end{array}$ \\
\hline $\mathrm{P}_{2} \mathrm{O}_{5}$ & 5,55 & 9,57 & 17,82 & 18,67 & $10,60(4,00-28,04)$ \\
\hline $\mathrm{SiO}_{2}$ & 80,23 & 69,64 & 45,61 & 34,89 & $70,88(21,62-88,26)$ \\
\hline $\mathrm{CaO}$ & 9,64 & 13,75 & 26,15 & 26,84 & $13,72(4,64-38,43)$ \\
\hline $\mathrm{MgO}$ & 0,27 & 0,30 & 0,53 & 2,07 & $0,44(0-5,92)$ \\
\hline $\mathrm{CO}_{2}$ & 1,20 & 1,51 & 3,14 & 6,79 & $1,94(0,17-13,06)$ \\
\hline $\mathrm{Fe}_{2} \mathrm{O}_{3}$ & 1,05 & 1,86 & 0,68 & 1,20 & $1,53(0,24-4,95)$ \\
\hline $\mathrm{Al}_{2} \mathrm{O}_{3}$ & 0,37 & 0,29 & 0,83 & 0,29 & $0,57(0,01-2,80)$ \\
\hline H. o. & 82,43 & 72,97 & 56,79 & 38,36 & $71,49(24,18-89,11)$ \\
\hline $\mathrm{Cl}$ & 0,08 & 0,01 & 0,01 & 0,003 & $0,08(0,001-0,24)$ \\
\hline $\mathrm{F}$ & 0,80 & 0,69 & 1,08 & 0,70 & $0,80(0,66-1,88)$ \\
\hline $\mathrm{Na}_{2} \mathrm{O}$ & 0,23 & 0,26 & 0,56 & 0,46 & $0,29(0,09-0,57)$ \\
\hline $\mathrm{K}_{2} \mathrm{O}$ & 0,30 & 0,13 & 0,12 & 0,09 & $0,22(0,05-0,43)$ \\
\hline $\mathrm{TiO}_{2}$ & 0,18 & 0,19 & 0,28 & 0,28 & $0,20(0,08-0,62)$ \\
\hline S (общая) & 0,85 & 0,90 & 0,83 & 0,78 & $0,85(0,23-1,46)$ \\
\hline Влага & 0,30 & 0,38 & 0,58 & 0,57 & - \\
\hline $\begin{array}{l}\text { Лимонно-ра } \\
\mathrm{P}_{2} \mathrm{O}_{5}\end{array}$ & 3,14 & 5,27 & 4,76 & 5,88 & $6,21 \quad(0,93-9,59)$ \\
\hline П. п. п. & 1,89 & 2,04 & 3,44 & 6,84 & $2,17(0,52-10,27)$ \\
\hline $\mathrm{SO}_{3}$ & 0,78 & 0,43 & 0,54 & 0,50 & $0,68(0,18-3,06)$ \\
\hline
\end{tabular}

приведен в табл. 3 , откуда видно, что средние содержания $\mathrm{P}_{2} \mathrm{O}_{5}, \mathrm{CaO}_{\text {, }}$ $\mathrm{CO}_{2}, \mathrm{MgO}, \mathrm{TiO}_{2}$ и процент потери при прокаливании (п.п.п.) возрастают от детритистого кварцевого песчаника в сторону брахиоподового конгломерата, т. е. сверху вниз по разрезу. Противоположная картина выявлена для $\mathrm{SiO}_{2}$, н. о., $\mathrm{K}_{2} \mathrm{O}$ и $\mathrm{Cl}$. 
Содержание лимонно-растворимого $\mathrm{P}_{2} \mathrm{O}_{5}$ возрастает главным образом с увеличением содержания $\mathrm{P}_{2} \mathrm{O}_{5}$. (рис. 1).

Содержание $\mathrm{F}$ в промышленном пласте фосфоритов колеблется в пределах $0,66-1,88 \%$, т. е. его немного больше по сравнению с Кингисеппским месторождением $(0,66-1,02 \%)$, но меньше по сравнению с Маардуским $(0,96-1,02 \%)$.

$\mathrm{P}$ аспределение $\mathrm{P}_{2} \mathrm{O}_{5}$ в промышленн ом пл асте. $\mathrm{P}_{2} \mathrm{O}_{5}$ основной полезный компонент, содержание которого находится в прямой зависимости от количества ракушек брахиопод и их детрита в терригенном материале. В разрезах буровых скважин концентрация $\mathrm{P}_{2} \mathrm{O}_{5}$ в про-

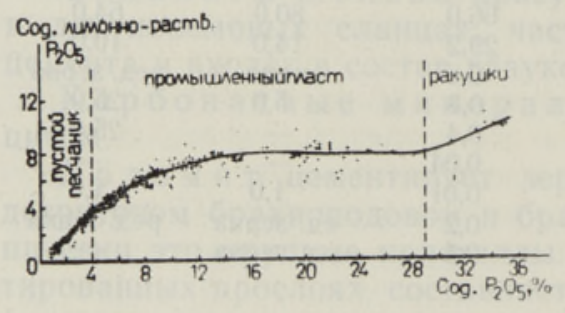

Рис. 1. Зависимость содержания лимонно-растворимого $\mathrm{P}_{2} \mathrm{O}_{5}$ от содержания $\mathrm{P}_{2} \mathrm{O}_{5}$ в фосфоритоносных песчаниках.

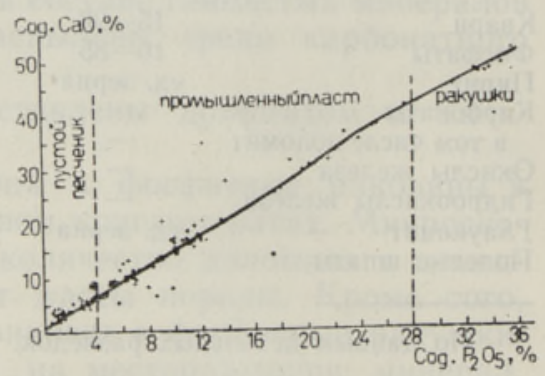

Рис. 2. Зависимость содержания $\mathrm{CaO}$ от содержания $\mathrm{P}_{2} \mathrm{O}_{5}$ в фосфоритоносных песчаниках.

мышленном пласте возрастает сверху вниз, достигая максимальной величины $(26-28 \%)$ в брахиоподовом конгломерате.

$\mathrm{B}$ пределах месторождения Тоолсе средние содержания $\mathrm{P}_{2} \mathrm{O}_{5}$ по скважинам колеблются в широких пределах: от 8 до $12-13 \%$, увеличиваясь в южном и особенно в юго-восточном направлениях (до 16-19\%). Повышению концентрации $\mathrm{P}_{2} \mathrm{O}_{5}$ соответствует уменьшение мощности промышленного пласта в этом же направлении. K западу и северо-западу проявляется противоположная тенденция.

Р аспределение $\mathrm{MgO}$ в промышленном пл асте. $\mathrm{MgO}-$ один из вредных компонентов в фосфатной руде. Особенно нежелательна концентрация $\mathrm{MgO}$ при производстве суперфосфата из фосфоритов. Его содержание в разрезах возрастает в основном сверху вниз, колеблясь от 0 до $5,92 \%$. Оно зависит не от содержания $\mathrm{P}_{2} \mathrm{O}_{5}$, а от состава и степени цемента. Если в детритистом кварцевом песчанике, детритовом песчанике и детритовом брахиоподовом конгломерате содержание $\mathrm{MgO}$ бывает от 0 до $1,0 \%$, то в брахиоподовом конгломерате наблюдается резкий скачок - более $1,5 \%$ вследствие присутствия в нем доломитового цемента.

Иногда довольно высокое содержание $\mathrm{MgO}$ отмечается и в самых верхних слоях промышленного пласта. В таком случае его содержание вниз по разрезу уменьшается, а в самых низах вновь повышается. На месторождении Тоолсе такие разрезы образуют отдельные пятна, а в южной и юго-восточной частях они занимают довольно большие участки. Повышение концентрации $\mathrm{MgO}$ в верхней и средней частях разрезов промышленного пласта связано, очевидно, со вторичными изменениями в зоне тектонических трещин.

Средние содержания $\mathrm{MgO}$ по скважинам колеблются в пределах $0,09-3,63 \%$, составляя в основном не более $0,2-1,0 \%$. 
Р аспределение $\mathrm{Fe}_{2} \mathrm{O}_{3}$ в промы шленном пл асте. Железо, как и магний, считается вредным компонентом фосфатной руды. Содержание общего $\mathrm{Fe}_{2} \mathrm{O}_{3}$ колеблется в пробах от 0,24 до 4,95\%, составляя обычно от 1,0 до $3,0 \%$.

B разрезах маардуской пачки концентрация $\mathrm{Fe}_{2} \mathrm{O}_{3}$ сверху вниз уменьшается, а в нижней части пачки $(0,3-1,2$ м) вновь повышается. Низы и верхи промышленного пласта содержат $\mathrm{Fe}_{2} \mathrm{O}_{3}$ примерно в равных количествах, однако, не во всех скважинах. Содержание железа крайне изменчиво и, как правило, не подчиняется никаким закономерностям. Такие разрезы чаще встречаются на юге и юго-востоке месторождения.

Средние содержания $\mathrm{Fe}_{2} \mathrm{O}_{3}$ по скважинам колеблются главным образом в пределах от 1 до $2 \%$, а в южной, юго-западной и юго-восточной частях месторождения достигают 2 и даже $3 \%$.

Р аспределение $\mathrm{CaO}$ в промышленном пл асте. Содержание $\mathrm{CaO}$ в руде колеблется в довольно широких пределах (табл. 3), увеличиваясь сверху вниз по разрезам. Относительно высокое содержание $\mathrm{CaO}$ в детритовом и брахиоподовом конгломератах вызвано, во-первых, присутствием в них карбонатного цемента и, во-вторых, высоким содержанием $\mathrm{CaO}$ в ракушках брахиопод.

Распределение концентрации $\mathrm{CaO}$ по площади не отличается равномерностью. Зависимость содержания $\mathrm{CaO}$ от содержания $\mathrm{P}_{2} \mathrm{O}_{5}$ - прямолинейная (рис. 2). По сравнению с другими месторождениями фосфоритов Эстонии содержание $\mathrm{CaO}$ в руде месторождения Тоолсе относительно высокое.

Таким образом, вещественный состав фосфоритоносных пород месторождения Тоолсе изучен относительно хорошо. Но тем не менее необходимы дополнительные исследования с тем, чтобы понять причины железистости фосфоритов и выяснить распространение их по площади.

\section{ЛИТЕРАТУ РА}

М устйыги обзор). Изв. АН ЭССР, Хим. Геол., 19, № 1.

Н а ли в к ин а А. И. 1973. Минералого-петрографическая характеристика фосфоритных руд месторождения Тоолсе. Информ. бюл. Сер.: Промышленность горнохимического сырья, вып. 2. Люберцы.

Р а уд се п Р. В. 1971. Месторождение фосфоритов Тоолсе. В сб.: Промышленность горнохимического сырья и природных солей, вып. 4. Люберцы.

K ivi mäg i E. 1971. Eesti fosforiidivarud. Eesti Loodus, nr. 5.

Управление геологии

Совета Министров Эстонской ССР
Поступнла в редакцию $13 /$ XI 1974

\section{R. RAUDSEP}

\section{TOOLSE LEIUKOHA FOSFORIIDI AINELISEST KOOSTISEST}

Viimastel aastakümnetel uuritud fosforiidileiukohtadest on Toolse suurim ja perspektiivikam.

Litoloogiliselt koostiselt on fosforiit kas liivakivi, mis sisaldab käsijalgsete fosfaatsete kodade tükke, või siis ainult nendest koosnev kivim - brahhiopoodkonglomeraat. Autori arvates on otstarbekas kivimid jaotada 5 erimiks (ülalt alla):

1) kvartsliivakivi;

2) detriidikas kvartsliivakivi;

3) detriitliivakivi;

4) detriitne brahhiopoodkonglomeraat;

5) brahhiopoodkonglomeraat. 
Mineraloogiliselt koostiselt on fosforiit küllaltki üksluine, sisaldades $90 \%$ kvartsi ja fosfaatseid mineraale, vähem teisi mineraale, nagu püriiti, kaltsiiti, dolomiiti, rauahüdroksiide ja silikaate, glaukoniiti, hüdrovilke, päevakive jne.

Keemilises koostises on kõige tähtsam $\mathrm{P}_{2} \mathrm{O}_{5}$-sisaldus, mis sõltub otseselt käsijalgsete kodade ja nende tükkide hulgast kivimis. Viimaste keemiline koostis ei erine oluliselt teiste fosforiidileiukohtade karpide omadest.

Vähem tähtis pole ka fosforiidis kui maavaras olevate kahjulike komponentide sisaldus. Nendeks on $\mathrm{MgO}, \mathrm{Fe}_{2} \mathrm{O}_{3}$ ja $\mathrm{CaO}$.

\section{R. RAUDSEP}

\section{ON THE MATERIAL COMPOSITION OF THE TOOLSE PHOSPHORITE DEPOSIT}

The phosphorite deposit of Toolse is the biggest and most prospective one of those studied in Soviet Estonia in recent years.

As to the lithological composition, the phosphorite is either sandstone containing fragments of brachiopod shells, or rock composed exclusively of the latter - brachiopod conglomerate. In the author's opinion, it is expedient to divide the rocks into 5 varieties (in the downward direction):

1) quartz sandstone;

2) detritic quartz sandstone;

3) detrite sandstone;

4) detritic brachiopod conglomerate;

5) brachiopod conglomerate.

Mineralogically, the phosphorite is of a rather one-sided composition, containing 90 per cent of quartz and phosphatic minerals, and small amounts of other minerals, such as pyrite, calcite, dolomite, ferrohydroxides and silicates, glauconite, hydromica, feldspar, etc.

In the chemical composition, of greatest importance is the content of $\mathrm{P}_{2} \mathrm{O}_{5}$, depending directly on the amount of brachiopod shells or their fragments in the rock. The chemical composition of those shells does not differ significantly from that of the shells found in other phosphorite deposits.

Of no lesser importance is the content of harmful components both in the phosphorite and the rock. Those components are $\mathrm{MgO}, \mathrm{Fe}_{2} \mathrm{O}_{3}$ and $\mathrm{CaO}$. 